\title{
Von Willebrand Disease, Type 2A
}

National Cancer Institute

\section{Source}

National Cancer Institute. von Willebrand Disease, Type 2A. NCI Thesaurus. Code C131686.

An autosomally inherited (generally dominant) coagulation disorder characterized by qualitative abnormalities of the von Willebrand factor (VWF). The mutant VWF causes decreased platelet adhesion due to a selective deficiency of high molecular weight multimers. The decrease in large multimers can be due to a failure to synthesize the multimers ('group 1') or enhanced ADAMTS13-mediated proteolysis of the secreted high molecular weight protein ('group 2'). 